\title{
Controlling the use of Tobacco for Sustainable Development: A Focus on India and South Africa
}

\author{
Theodore Duxbury ${ }^{1}$, Seema Rath ${ }^{2}$, Paayal Maraj', Sean James Bosman ${ }^{3}$, Sunitha Srinivas ${ }^{1^{\star}}$ \\ ${ }^{1}$ Faculty of Pharmacy, Rhodes University PO Box 94, Grahamstown, SOUTH AFRICA. \\ ${ }^{2}$ Hugh Kelly Fellow, Faculty of Pharmacy, Rhodes University, SOUTH AFRICA /Department of Economics, Government College, \\ Khandola-Goa, INDIA. \\ ${ }^{3}$ Department of English, Rhodes University, Grahamstown, SOUTH AFRICA.
}

\begin{abstract}
The use of tobacco containing products is a global health and economic burden adversely affecting sustainable development, particularly in the developing world. This article focuses on the impact of population growth, aging, gender, culture, and the ascendancy of transnational tobacco companies on the tobacco epidemic in India and South Africa. There is a distinctive manifestation of the tobacco epidemic in India and South Africa based on the stated impacting factors. Successful implementation and execution of tobacco control policies are required to promote sustainable human development. These must act in conjunction with strengthened World Health Organization tobacco control measures and improved understandings of tobacco industry strategies, as well as take population attitudes and practices towards tobacco consumption into consideration. One of the most effective contributions to controlling the tobacco epidemic is seen in health promotion initiatives.
\end{abstract}

Key words: Tobacco, Health, Health Promotion, Sustainable Development Goals, Tobacco control polices.

\section{INTRODUCTION}

Tobacco use has become a global epidemic, with dire consequences on health and development. ${ }^{1,2}$ It is estimated that the number of tobacco smokers will increase to 1.6 billion within the next 25 years. It is also estimated that there are close to 1 billion male and 0.25 billion female tobacco smokers globally, with 99000 young individuals starting to smoke their first tobacco product annually. It is indicated that the majority of this youth group are children under the age of ten, residing in low- and middle-income countries (LMICs). This epidemic is shifting from high-income countries to LMICs with the industry's activities specifically targeted at youth and women. ${ }^{3}$ It is reported that nearly $80 \%$ of the world's 1 billion smokers reside in LMICs and it is within these countries that tobacco-related illnesses are most common. ${ }^{3}$ Reports suggest that one of the reasons transnational tobacco companies aim their marketing at women and children is to compensate for those who quit or die due to tobacco related diseases. Tobacco use poses one of the leading preventable public health threats in the world. ${ }^{4}$

This manuscript focuses on tobacco use prevalence and its influence on the Sustainable Development Goals (SDGs) under existing tobacco control policies and legislation in India and South Africa. The literature is based on policy measures set out by the World Health Organization (WHO) which includes the Framework Convention on Tobacco Control policies and the MPOWER measures.

\section{TOBACCO USE PREVELANCE}

Certain factors which influence the use of tobacco include age, gender, culture and economic characteristics. Smoking tobacco in men and women is historically most common in high-income countries (HICs) in higher socio-economic groups, but is now shifting towards lower socio-economic
DOI: 10.5530/ijopp.9.2.5

Address for correspondence: Sunitha Chandrasekhar Srinivas,

Faculty of Pharmacy,

Rhodes University PO Box 94, Grahamstown, SOUTH AFRICA.

Phone no: + 27466038496 E-mail: s.srinivas@ru.ac.za

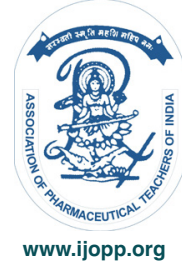


groups and LMICs. The major contributor to this shift is the expansion of transnational tobacco companies marketing $70 \%$ of their cigarettes in Asia, Africa, Eastern Europe and Latin America. ${ }^{5,6}$ Global statistics indicate that tobacco use is more widespread amongst men than women, and that age-standardized smoking prevalence is gradually decreasing across all continents. High levels of smoking can be associated with those below 20 years of age, and evidence states that health warnings tend to be ignored by those who are starting to smoke. ${ }^{5}$ There is a gradual decline in tobacco users in some HICs and upper middle-income countries (UMICs), but a disturbingly high increase amongst LMICs, resulting in a global increase in the consumption of tobacco products. Rapid population growth can also have an effect on tobacco use, further influencing the youth and women, and strengthening the tobacco industries' economic hold on them, especially in South Africa, with a projected population of 60 million by 2030 (Table 1).

The United Nations predicts that by 2050 the population over 60 years of age will account for approximately half of the world population., This geriatric population is projected to increase for both India and South Africa by 2030 (Table 1), leading to increasing demand for healthcare due to a higher prevalence of non-communicable diseases (NCDs). This will have negative implications on the proposed healthcare budget for the government as well as on the health expenditure of patients.

\section{Demographics}

Increases in the size of a population can be regarded as a contributing factor to economic development as they enhance the demand for goods and services, and increase the supply of workforce, in turn encouraging an increase in production, employment and income. The African Region has over $30 \%$ of its population between the ages of 10 and 24, with these figures predicted to remain consistent over the next 15 years. The prominence of youth in the population and the importance of improving health behaviours and services for adolescents require much more attention in many countries if it has to result in demographic dividend. ${ }^{10}$ Even in India and South Africa, a larger proportion of population belongs to the age group of 15 to 69 years, the 'most productive age group', which is predicted to increase further (Table 1). This demonstrates that if the available human resource is used efficiently, in a non-exploitative and non-capitalistic way by all parties involved, it will result in sustainable development. However, ill health is a key factor that disrupts this critical growth and development cycle, and contributes to the drop in life expectancy, ${ }^{10,11}$ especially healthy life expectancy. A study reports that tobacco smoking habits reduce the life expectancy of smokers by 12 years. ${ }^{5}$

\section{Tobacco use prevalence in India and South Africa}

In India and South Africa, smoking initiation typically occurs during the late teenage years and the early twenties, and has a much higher prevalence amongst males than females. ${ }^{12,13}$ In South Africa, it is reported that females who lost their mothers before they had turned 15 years of age are more likely to start smoking than those who had not. Males and females who currently drink alcohol once or twice a week are also more likely to start smoking than those who do not. ${ }^{14}$ The tobacco market within South Africa consists of 7.7 million tobacco users. ${ }^{15}$ Smoking tobacco is the most common method of tobacco consumption amongst South Africans. ${ }^{16}$ The use of other tobacco products is significantly higher in rural, informal settings (83.2\%) than in urban, formal settings $(56.2 \%) .{ }^{16}$ Furthermore, current smokers in informal urban settings smoke 6.5 cigarettes per day as opposed to the national average of 7.4 cigarettes per day. The report indicates that previous exposure to environmental tobacco smoke (ETS), also known as passive smoking, has an influence on the likelihood of future tobacco use. Around $17.7 \%$ of the population is exposed to ETS on a daily basis in their home environment. The contribution of ETS is significantly higher for males than for females, especially for Coloured males, and this

\begin{tabular}{|c|c|c|c|c|c|c|}
\hline \multirow[t]{2}{*}{ Age Group } & 2010 & 2015 & 2030 & 2010 & 2015 & 2030 \\
\hline & \multicolumn{3}{|c|}{ Projected } & \multicolumn{3}{|c|}{ Projected } \\
\hline $0-14$ & 30.89 & 28.79 & 23.90 & 30.93 & 29.25 & 25.40 \\
\hline $15-29$ & 27.57 & 27.03 & 24.24 & 29.65 & 29.16 & 25.80 \\
\hline $30-69$ & 38.43 & 40.77 & 46.64 & 36.07 & 38.42 & 44.52 \\
\hline 70 and above & 3.10 & 3.41 & 5.22 & 3.34 & 3.18 & 4.30 \\
\hline Total & 100.00 & 100.00 & 100.00 & 100.00 & 100.00 & 100.00 \\
\hline (in millions) & 1230.99 & 1311.05 & 1527.66 & 51.62 & 54.49 & 60.03 \\
\hline
\end{tabular}

Source: The United Nations, $2015 .^{7}$ 


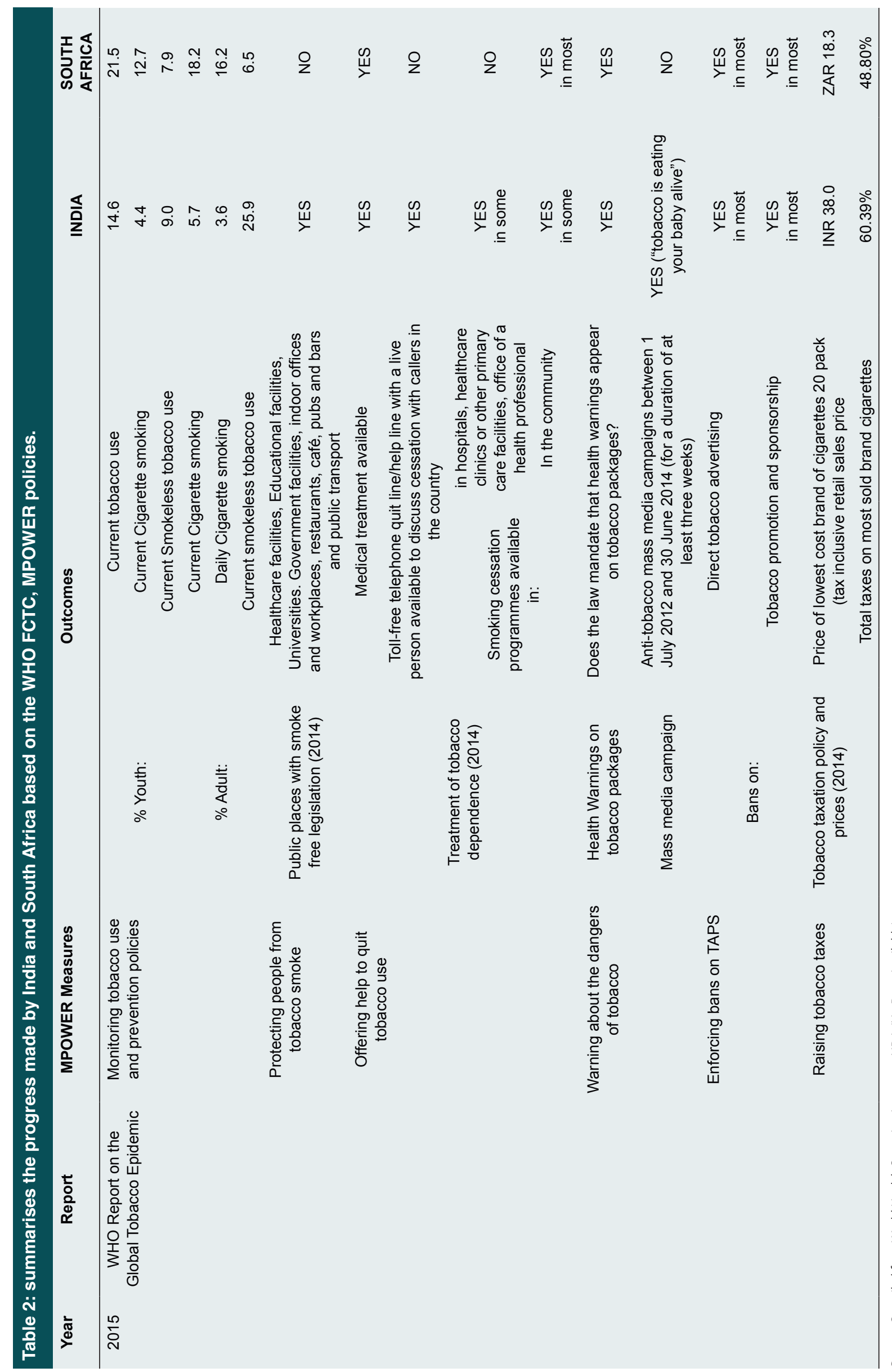


Table 3: South Africa's Tobacco control policies and legislation

\begin{tabular}{|c|c|c|}
\hline Year & Report & Outcomes \\
\hline 1993 & The Tobacco Products Control Act 83 & $\begin{array}{c}\text { Bans on advertising and sponsorship, smoking in public } \\
\text { places and free distribution and reward; restrictions } \\
\text { on vending machines; provides for fines; provides for } \\
\text { maximum yields of constituents }\end{array}$ \\
\hline 1994 & $\begin{array}{c}\text { Regulations on labelling, advertising and sale of tobacco } \\
\text { products }\end{array}$ & $\begin{array}{l}\text { Inclusion of prescribed health warnings on packages and } \\
\text { other requirements for labelling and packaging }\end{array}$ \\
\hline 2000 & $\begin{array}{c}\text { Regulations: "Notice relating to the maximum permissible } \\
\text { yield of tar, } \\
\text { nicotine and other constituents in tobacco products" }\end{array}$ & $\begin{array}{l}\text { To control tar and nicotine levels within tobacco products. } \\
\text { Defined smoking in public places. Point of sale display } \\
\text { media regulations. }\end{array}$ \\
\hline 2005 & \multicolumn{2}{|c|}{ World Health Organization Framework Convention on Tobacco Control } \\
\hline 2007 & Tobacco Products Control Amendment Act 23 & Aspects that entered into force as of 21 august 2009 \\
\hline 2008 & The Tobacco Products Control Amendment Act of 2008 & $\begin{array}{l}\text { Restrictions on Smoking in public places and vehicles. } \\
\text { Sales bans and restrictions for persons below } 18 \text { years. }\end{array}$ \\
\hline 2011 & $\begin{array}{l}\text { Regulations on reduced Ignition Propensity (RIP), } 16 \text { May } \\
\qquad 2011\end{array}$ & $\begin{array}{l}\text { introduces standards for manufacturing of reduced ignition } \\
\text { propensity cigarettes }\end{array}$ \\
\hline
\end{tabular}

Source: Tobacco Institute of Southern Africa, 2013.

may be a contributing factor to males having a higher tobacco consumption rate than females. ${ }^{14}$ The fact is that the proportion of those smokers from rural formal settings who reported trying to quit their smoking habits $(34.7 \%)$ was significantly lower than those from urban formal $(49.9 \%)$ and urban informal $(56.9 \%)$ settings. ${ }^{17}$

India has a very high percentage of youth and adults consuming smokeless tobacco and a lower percentage for cigarette smoking in comparison to South Africa (Table 3). India has more traditional ways of consuming tobacco, such as the use of a hookah, more prevalent in rural than in urban areas, which are slowly being phased out by the use of bidis and cigarettes. ${ }^{13,18}$ For many years, tobacco has been consumed by wrapping it inside a betel leaf, which is then placed inside the mouth or chewed. In Southern India, the most common form of tobacco consumption is the use of a bidi, which contains $0.15-0.25 \mathrm{~g}$ sun-dried flaked tobacco rolled into a conical shape in a dried piece of Temburni leaf. ${ }^{19}$ Bidi is 7-8 times more common in India than the conventional cigarette and is used more prevalently by men than women. Smoking of tobacco in most parts of India, with the exception of Punjab, Maharashtra and Sikkim, is reported as prevalent in one quarter to a half of adult men above the age of 15 . Female smoking is prevalent in states such as Jammu, Kashmir and Bihar. ${ }^{18}$ In India, the use of tobacco amongst poor underprivileged communities is a major concern exacerbated by lower educational levels, socio-economic status, having a father who used tobacco, and the province of residence. ${ }^{20-22}$ The health risks consequential to the use of tobacco are to some extent associated with the method of consumption.

\section{HEALTH CONSEQUENCES OF TOBACCO USE}

Tobacco use affects almost every organ in the body, resulting in various types of cancers, respiratory and cardiovascular diseases, diabetes, certain eye disorders, weakening of the immune system, rheumatoid arthritis, and erectile dysfunction. ${ }^{23}$ Tobacco is one of the largest contributing risk factors of non-communicable diseases (NCDs). There are nearly six million global NCD mortality incidences every year, with more than 10 per cent of these deaths occurring amongst non-smokers, including children who are being exposed to secondhand smoke. ${ }^{24,25}$ Passive smoking is hazardous to infants and children and causes various health problems, such as more frequent and severe asthma attacks, respiratory infections, ear infections and sudden infant death syndrome (SIDS). ${ }^{26}$ Tobacco consumption and the dangers of passive smoking have a major impact on child health in less apparent ways, namely: hunger and malnutrition; the exploitation of youth as workers in tobacco farming; tobacco related diseases; and mortality which arises from fires caused by cigarettes. ${ }^{27,28}$ These factors contribute to the increasing burden of NCDs and can be linked to the increasing costs of treatment and decreasing economic productivity.

The WHO predicts that by 2030 tobacco will contribute towards more than eight million people's deaths annually, and that four out of five of these will occur in LMICs. Tobacco use remains one of the leading causes of premature preventable deaths, with 44000 deaths per year, which equals approximately 120 deaths per day. ${ }^{29,30}$ These deaths are caused by the hazardous chemicals contained in the smoke of tobacco products, some of which are: formaldehyde; benzene; and nicotine. ${ }^{31}$ Nicotine is a highly addictive psychoactive ingredient in tobacco products. ${ }^{32}$ According to a chemical analysis 
done on bidi smoke, the overall toxicity as measured by tar, nicotine, ammonia, carbon dioxide, hydrogen cyanide, other volatile phenols and carcinogenic hydrocarbons and radioactive uranium, is higher in bidis than in cigarettes. The study also reported that bidi smoking results in higher intake of carbon monoxide, nicotine and tar, due to the porosity of Tendupatta (Diospyros melanoxylon) leaves. ${ }^{33,34}$

A South African survey revealed a particular increase in 'roll-your-own cigarette' (RYO) practices amongst the indigenous and lower socio-economic community, despite the decrease in the prevalence of cigarette smoking due to the implementation of comprehensive tobacco control legislation and 'sin tax' in particular. ${ }^{35}$ According to a monitoring and evaluation report produced by the Southern Africa Resilience Innovation Lab, School of Health Systems and Public Health, RYO cigarettes pose a greater health risk than factory produced cigarettes due to a difference in weight, diameter, packing density and porosity of the wrapping paper. ${ }^{36}$ Studies report that RYO cigarettes require more puffs, and the smoker therefore inhales more smoke per cigarette for a longer period of time, exposing themselves to a wider range of carcinogens and other harmful substances.

\section{Tobacco Use and its Impact on Sustainable Development Goals 3}

SDG 3.4 focusses on reducing mortality from NCDs, and SDG Target 3.a aims at strengthening the implementation of a framework convention on tobacco control elaborated in Table 3. The Global SDG targetaims to reduce the use of tobacco by $30 \%$ by 2030 , while Indian Health Target aims to reduce it by $15 \%$ by 2020 and by $30 \%$ by 2025 and South African Health Targets are set at $20 \%$ reduction by $2020 .^{30,37,38}$ Every 1 in 4 Indians risk death before they reach the age of 70 years from NCDs such as heart and lung disease, cancer, stroke and diabetes. ${ }^{38}$

Tobacco use has various adverse consequences on sustainable development goals affecting neonatal and maternal morbidity and mortality; communicable diseases; and road traffic accidents. Studies have shown that maternal tobacco smoking can cause a three-fold increased risk of Sudden Infant Death Syndrome (SIDS)..$^{39}$ Sleep-related obstructive apnoeic episodes and decreased lung function are also concerns associated with smoking tobacco. South Africa's increasing burdens of tuberculosis (TB) and HIV/AIDS only aggravate the health impacts of smoking. According to the WHO, $99 \%$ of maternal and neonatal mortality occurs within the developing world. South Africa has high levels of maternal (132.9 per 100,000 in 2012-13) and child mortality (41 per 1000 live births in 2015) ${ }^{40}$ and these are inseparably linked to NCDs as well as to their risk factors. ${ }^{41-43}$ Smoking also affects Sustainable Development Goal 3.6, which aims to halve the number of global deaths and injuries resulting from road traffic accidents by 2020. A study conducted on "Smoking while driving and its consequences on road safety" reports evidence that smoking while driving generates a significant risk to road safety, higher than that of mobile phone use. ${ }^{44}$

\section{Tobacco and Poverty}

The burden of disease that results from tobacco use places financial strain on the government's health and development budgets as well as on individual household budgets. The World Bank reports that the percentage of South Africa's population below the National Poverty Line in 2013 was 53.8\%, with a Gross National Income (GNI) Per Capita of (2011 PPP\$) 12,122 in 2014. According to the WHO, $80 \%$ of South Africa's population depends on public healthcare services. Tobacco consumers contribute to poverty by using their income to buy tobacco products, which influences the loss of productivity, increased incidence of diseases, and death. ${ }^{45,46}$ South Africa has a very low economically active population that accounted for only $35 \%$ of the total population in $2010 .{ }^{47}$ In underprivileged households, large amounts of money are spent on the use of tobacco, which decreases the money that could be spent on essential needs such as food, shelter, sanitation, education, and healthcare. A lack of finances caused by tobacco expenditure could increase the rates of malnutrition, which is one of the leading causes of mortality in the underprivileged populations of South Africa. As this vicious cycle escalates, social, personal, and medical disadvantages will be a norm for those who spend most of their income indulging in a NCD risk factor. ${ }^{48}$

In 2001, India's 35-69 years population spent Rs 1.48 trillion (US\$22.4 billion) on tobacco related diseases, with $16 \%$ of this expenditure going to direct medical costs and $84 \%$ to indirect morbidity costs. It is reported that $91 \%$ of the economic burden of total tobaccoconsumption was as a result of male tobacco consumers. Overall, the economic burden of tobacco use was highest due to cardiovascular diseases. In the case of females, the burden of diseases due to tobacco consumption was highest for cancers (38\%), followed by CVDs (18\%), tuberculosis $(17 \%)$ and respiratory diseases $(1.4 \%){ }^{49}$ According to the Indian Council of Medical Research, cancer, heart disease and COPD, which are all preventable non-communicable diseases, cost the country Rs 277.61 billion (US\$ 4.18 billion). Thus it is evident that tobacco related diseases have enormous economic and health consequences within these two developing countries. 
Health issues associated with being employed by the tobacco industry is another important aspect. In India, a large percentage of employees of the tobacco industry are women (60\%), along with children (12-15\%), who are mostly young girls. Cultivation of tobacco causes Green Tobacco Sickness (GTS) to those involved directly with the cultivation, greatly affecting children of poor households employed in tobacco farming to provide family income. ${ }^{3,50}$ Even though the tobacco industry improves short-term economic conditions through employment, the cost of tobacco use far outweighs the monetary gain, negating sustainable human development.

\section{MEASURES TO CONTROL TOBACCO USE}

\section{Tobacco taxes}

Increasing the taxes charged on tobacco products is one of the most effective ways to reduce tobacco consumption and the effects thereof, and it could also generate revenue for a country. ${ }^{45}$ A ZAR1.00 (US\$ 0.06780 ) increase in the price of cigarettes reduces the risk of smoking onset by $1.1 \%-2.8 \%$ in males, which is the highest tobacco consuming population in South Africa. ${ }^{14}$ The South African government utilizes the "sin tax" strategy to complement ad-marketing approaches towards tobacco products, by placing extreme tax increases on tobacco products over the years, from 1980 to present. ${ }^{5,51}$ However, tobacco is a habit creating item, with a highly inelastic demand, so raising tax on it may not affect the demand for the product. Increased prices also result in tobacco users resorting to low-cost brands, 'rolling' their own tobacco-containing products, and illicit trade, which in turn is increasingly detrimental to public health. ${ }^{52,53}$ It is reported that there was a substantial increase in the illicit trade of cigarettes in 2010, peaking in $2011 .^{54}$ It is therefore essential not only to focus on cigarette prices but also on controlling alternative methods of tobacco consumption more effectively. If urgent actions are not taken, the economic and health burden of tobacco use could continue to push the families of millions of tobacco users towards poverty, and steadily decelerate the economic development of both South Africa and India.

\section{Tobacco industry and its approach to interfere with tobacco control}

The WHO Committee of Experts on Tobacco Industry Documents reports on tobacco industry tactics designed to interfere with tobacco control, which include: establishing unethical liaisons with WHO staff; use of their financial power as an influence over policies and the subsequent fine print; leveraging influence through other United Nations agencies; discrediting WHO or WHO officials; distorting WHO research; and use of media events to distract from tobacco control initiatives. ${ }^{55}$

Tobacco industry spends large amounts on advertising, as evinced by the fact that the South African tobacco industry spent nearly 240 million Rand (US\$ 15.8 million) a year on advertising and promotions between 1996 and 1998. However, the tobacco industry claimed that these actions were merely to compete for market share, without any net influence on smoking. ${ }^{56}$ The tobacco industry lost a court case challenging the South African Government's proposed amendments to the Tobacco Products Control Act 1993, basing their arguments largely on the economic consequences to South Africa in the form of loss of revenue and a projected loss of employment (approximately 15000 people). ${ }^{5}$ Various groups, such as the Freedom of Commercial Speech Trust, the South African Chamber of Business, and the Council of South Africa Banks, all lobbied against the proposed advertising bans. Other entities, such as the Food and Allied Workers Union, international experts, and sport and cultural recipients of tobacco sponsorships were all influenced to testify against the proposed 1993 Act. ${ }^{57}$ These are just some of the examples of the subversive tactics that the tobacco industry continues to resort to in its efforts to undermine tobacco control policies and initiatives.

However, the industry and its supporters overlook the real cost of production and consumption of tobacco affecting the health of the society. The profit motivated and short sighted analysis of control of tobacco does not consider the detrimental impact of increased availability and consumption of tobacco on the youth and its productive population, thereby ignoring the cost to sustainable human development.

\section{Tobacco policies and legislation}

In 1979, the WHO Expert Committee on Smoking Control proposed that the WHO use its international treaty establishing powers to draw up an international regulatory mechanism for tobacco control at the World Health Assembly. This action led to the establishment of the WHO Framework Convention on Tobacco Control (WHO FCTC) in 2005, which calls for international co-ordination of tobacco control, requiring signatory governments to impose a certain number of minimum tobacco control interventions in their respective countries. On 19 April 2005, South Africa confirmed the adoption of the WHO FCTC, and subsequently made it their vision to strive for a tobaccofree society. In February 2005, India initiated the implementation of the WHO FCTC policies. 
The WHO FCTC states that monitoring provides policy-makers and public health authorities with important information on:

- The extent to which the tobacco epidemic is a concern in the country

- The identification of subgroups in need of tailored policies and programmes

- Public awareness and attitudes towards the tobacco epidemic, and the control thereof

- Possible changes with regard to tobacco use after the implementation of policies and programmes

- How government and society comply and enforce tobacco control policies

- Tobacco industry tactics utilized to interfere and hinder the implementation of tobacco control policies and programmes. ${ }^{60}$

In 2008 the WHO mobilized a global initiative to support the implementation of the WHO FCTC policy measures, especially by developing countries. The initiative was called MPOWER and comprised of the following 6 measures:

M: Monitoring tobacco use and prevention policies

P: Protecting people from tobacco smoke

O: Offering help to quit tobacco use

W: Warning about the dangers of tobacco

E: Enforcing bans on tobacco advertising, promotion and sponsorship

R: Raising tobacco taxes ${ }^{58}$

As per Table 2, South Africa's progress in the implementation of the WHO FCTC MPOWER contradicts reports presented by the country with regards to certain aspects such as the impact of legislation regarding public smoke-free places (Table 3). South Africa has improved in terms of tobacco regulation and policy implementation, especially after the commencement of the Tobacco Products Control Act 83 of 1993 on 1 February 1994, and its subsequent amendments (Table 3). It is encouraging to see that South Africa is making progress with education, communication, training, and public awareness of tobacco control initiatives, targeted at both children and adults. Not only did the 1993 Act address the use of tobacco in South Africa, it also afforded non-smokers the right to air that is unpolluted by tobacco smoke. ${ }^{52}$ Hence, regular updates on progress reports are essential for development, as the monitoring and evaluation (M, E) of programmes assist with problem solving. M,E allows one to review and assess the progress made towards set objectives, by identifying problems and strategies and making adjustments to plans. ${ }^{59}$

\section{DISCUSSION}

It is essential to evaluate the effectiveness of the implementation of the MPOWER measures in the areas where tobacco use is on the rise, especially in LMICs, and to monitor systems which are currently classified as 'weak' according to the WHO. Regular anti-tobacco mass-media campaigns would assist greatly in the cessation and prevention of smoking, and ought to be a common practise. ${ }^{61}$ By prohibiting the sale of cigarettes in individual quantity (or "loose" cigarettes) or in small packets, smoking prevalence could be decreased, especially amongst the youth and lower socio-economic sections of the population.

Studies indicate that only a small number of people comprehend the specific health risks of tobacco use. ${ }^{62}$ This is indicative of the large gap in health related knowledge within the global population. Focus should not only be placed on disease treatment, but also on disease prevention, through supporting and strengthening public health promotion initiatives within the populations most affected, using a bottom-up approach..$^{63}$ Disease prevention aids the reduction of costs that individuals, employees, medical facilities, insurance companies, and governments incur on medical treatment, as a consequence of NCDs resulting from tobacco use. Society requires public health promotion initiatives to take ownership and needs to live sustainably. Promoting tobacco control activities in schools may help to support WHO FCTC policies. India and South Africa need to focus on preventing the use of tobacco, mainly within the child, youth and female population, by resorting to appropriate education and awareness campaigns that would help to create a healthier population for sustainable development.

\section{CONCLUSION}

The tobacco epidemic diversely affects sustainable development, especially in the developing world, specifically SDGs 1-3, 5 and 8 . As a result of different demographic factors, culture, beliefs, and the impact of tobacco companies, the manifestation of the tobacco epidemic within India and South Africa is variable with regard to its implications. The WHO and the United Nations suggest that these governments strengthen the implementation of the WHO MPOWER measures and that they also empower individuals to take ownership of their own health through health promotion initiatives.

\section{ACKNOWLEDGEMENT}

The authors gratefully acknowledge Rhodes University for all its support. 


\section{CONFLICT OF INTEREST}

No conflict of interest.

\section{ABBREVIATION USED}

HICs: High Income Countries; LMICs: Low- and middle-income countries; UMICs: Upper middle income countries; WHO: World Health Organization; FCTC: Framework Convention on Tobacco Control; ETS: Environmental Tobacco Smoke; NCD(s): NonCommunicable Diseases; HIV/AIDS: Human Immunodeficiency Virus/Acquired Immune Deficiency Syndrome; SIDS: Sudden Infant Death Syndrome; SDG(s): Sustainable Development Goals; M,E: Monitoring and Evaluation; GNI: Gross National Income; PPP: Per person Per; NDA: No Data Available; RYO: Roll your own.

\section{REFERENCES}

1. Van Zyl-Smit RN, Allwood B, Stickells D, Symons G, Abdool-Gaffar S, Murphy K, et al. South African tobacco smoking cessation clinical practice guideline. S Afr Med J. 2013;103(11):869.

2. WHO. WHO framework convention on tobacco control [Internet]. 2005. Available from: http://www.who.int/tobacco/framework/WHO_FCTC_english.pdf

3. WHO. Tobacco: Key Facts [Internet]. WHO. 2015 [cited 2016 Apr 3]. Available from: http://www.who.int/mediacentre/factsheets/fs339/en/

4. Lando H, Hipple B, Muramoto M, Klein J, Prokhorov A, Ossip D, et al. Tobacco is a global paediatric concern. Bull World Health Organ. 2010;88(1):2-2.

5. Fourie, Leon De W, De Jager, Johan. The impact of legislative changes in the tobacco industry on South Africans-clearing the air. 2003 [cited 2016 Feb 8];6(2). Available from: http://reference.sabinet.co.za/document/AJA10158812_14

6. World Conference on Tobacco or Health. Tobacco and poverty [Internet]. 2015. Available from: http://www.wctoh.org/media/wctoh-2015-press-kit/document/ FS8-Tobacco-and-Poverty-2015.pdf

7. United Nations, 2015. World Population Prospects-Population Division [WWW Document]. URL http://esa.un.org/unpd/wpp/(accessed 3.14.16).

8. United Nations, Department of Economic and Social Affairs, Population Division. World Population Ageing 2013 [Internet]. 2013 [cited 2016 Mar 17]. Available from: http://www.un.org/en/development/desa/population/publications/pdf/ ageing/WorldPopulationAgeing2013.pdf

9. United Nations Department of Economic and Social Affairs, Population Division. Executive summary [Internet]. 2007 [cited 2016 Mar 17]. Available from: http:// www.un.org/esa/population/publications/WPA2007/ES-English.pdf

10. Lee R, Reher D. Demographic transition and its consequences. In: Population and development review. 2011.

11. Bloom DE, Canning D. Population Health and Economic Growth. In: Growth Commission [Internet]. 2008. 53-75. Available from: http://siteresources. worldbank.org/EXTPREMNET/Resources/489960-1338997241035/Growth_ Commission_Vol2_Health_Growth_Ch3_Population_Health_Economic_ Growth.pdf

12. Chadda R, Sengupta S. Tobacco use by Indian adolescents. Toblnduc Dis. 2002;1(1):8.

13. Garg A, Singh MM, Gupta VK, Garg S, Daga MK, Saha R. Prevalence and correlates of tobacco smoking, awareness of hazards, and quitting behavior among persons aged 30 years or above in a resettlement colony of Delhi, India. Lung India Off Organ Indian Chest Soc. 2012;29(4):336-40.

14. Department of Economics University of Cape Town. Determinants of Smoking Initiation in South Africa. 2013; Available from: http://tobaccoecon.org/wpcontent/uploads/2013/11/determinants-of-smoking-initiation-in-south-africa.pdf

15. The Tobacco Institute of Southern Africa. Tobacco in South Africa [Internet]. 2013 [cited 2016 Feb 10]. Available from: http://www.tobaccosa.co.za/browse. php? catid $=105 \&$ sub $=166$
16. Human Science Research Council. The South African National Examination Survey.Human Sciences Research Council; 2012.

17. Institute for Security Studies. Population futures: revisiting South Africa's national development plan 2030 [Internet]. 2013. Available from: https://www. issafrica.org/uploads/AF7_15Oct2013V2.pdf

18. Jindal SK, Aggarwal AN, Chaudhry K, Chhabra SK, D'Souza GA, Gupta D, et al. Tobacco Smoking in India: Prevalence, Quit-rates and Respiratory Morbidity [Internet]. 2005 [cited 2016 Mar 17]. Available from: http://medind.nic. in/iae/t06/i1/iaet06i1p37.pdf

19. Jayalekshmi PA, Gangadharan P, Akiba S, Koriyama C, Nair RRK. Oral cavity cancer risk in relation to tobacco chewing and bidi smoking among men in Karunagappally, Kerala, India: Karunagappally cohort study. Cancer Sci. 2011;102(2):460-7.

20. Gilani SI, Leon DA. Prevalence and sociodemographic determinants of tobacco use among adults in Pakistan: findings of a nationwide survey conducted in 2012. Popul Health Metr. 2013;11:16.

21. Rani M, Bonu S, Jha P, Nguyen SN, Jamjoum L. Tobacco use in India: prevalence and predictors of smoking and chewing in a national cross sectional household survey. Tob Control. 2003;12(4):e4-e4.

22. Singh A, Ladusingh L. Prevalence and Determinants of Tobacco Use in India: Evidence from Recent Global Adult Tobacco Survey Data. PLoS ONE [Internet]. 2014 Dec 4 [cited 2016 Mar 16];9(12). Available from: http://www.ncbi.nlm.nih. gov/pmc/articles/PMC4256395/

23. CDC. Smoking and Tobacco Use; Fact Sheet; Health Effects of Cigarette Smoking [Internet].Smoking and Tobacco Use. 2015 [cited 2016 Feb 10]. Available from: http://www.cdc.gov/tobacco/data_statistics/fact_sheets/health_ effects/effects_cig_smoking/

24. WHO. Mortality and burden of disease from second-hand smoke [Internet]. WHO. 2016 [cited 2016 Feb 9]. Available from: http://www.who.int/gho/phe/ secondhand_smoke/en/

25. WHO FCTC. WHO Framework Convention on Tobacco Control [Internet]. 2013. Available from: http://www.who.int/tobacco/global_report/2013/who_fctc. pdf?ua=1

26. CDC. Smoking and Tobacco Use; Fact Sheet; Health Effects of Secondhand Smoke [Internet].Smoking and Tobacco Use. 2016 [cited 2016 Mar 18]. Available from: http://www.cdc.gov/tobacco/data_statistics/fact_sheets/ secondhand_smoke/health_effects/

27. International Diabetes federation, International union against Tuberculosis and lung disease, Global Cancer Control, World Health Federation. A Focus on Children and Non-Communicable Diseases (NCDs) [Internet]. 2011. Available from: https://ncdalliance.org/sites/default/files/resource_files/20110627_A_Focus_ on_Children_\&_NCDs_FINAL_2.pdf

28. Murray CJL, Alan D Lopez. Global mortality, disability, and the contribution of risk factors: Global Burden of Disease Study. 1997;

29. KZN DoH. Key facts [Internet]. 2014. Available from: http://www.kznhealth.gov. za/World_no_tobacco_day_31052014.htm

30. WHO. Global action plan for the prevention and control of non-communicable diseases, 2013-2020 [Internet]. 2013. Available from: http://apps.who.int/iris/ bitstream/10665/94384/1/9789241506236_eng.pdf

31. CDC. Smoking and Tobacco Use; 2010 Surgeon General's Report; Chemicals in Tobacco Smoke [Internet].Smoking and Tobacco Use. 2011 [cited 2016 Jan 28]. Available from: http://www.cdc.gov/tobacco/data_statistics/sgr/2010/ consumer_booklet/chemicals_smoke/

32. WHO. Tobacco [Internet].WHO. 2016 [cited 2016 Feb 5]. Available from: http:// www.who.int/topics/tobacco/en/

33. Gupta PC, Asma S. Bidi Smoking and Public Health [Internet]. 2008 [cited 2016 Mar 17]. Available from: http://www.who.int/tobacco/publications/prod_ regulation/bidi_smoking_public_health.pdf

34. Rahman M, Fukui T. Bidi smoking and health. Public Health. 2000;114(2):123-7.

35. Ayo-Yusuf OA, Olutola BG. "Roll-your-own" cigarette smoking in South Africa between 2007 and 2010. BMC Public Health. 2013;13(1):597.

36. Southern Africa Resilience Innovation Lab, School of Health Systems and Public Health. The use of roll-your-own cigarettes in South Africa.Public Health Association of South Africa [Internet]. 2014 [cited 2016 Mar 17]; Available from: https://www.phasa.org.za/use-roll-cigarettes-south-africa/

37. WHO. Towards a monitoring framework with targets and indicators for the health goals of the post-2015 Sustainable Development Goals. January 2015 Draft [Internet]. 2015 [cited 2016 Mar 14]. Available from: http://www.who.int/ healthinfo/indicators/hsi_indicators_sdg_targetindicators_draft.pdf 
38. WHO. India: first to adapt the Global Monitoring Framework on noncommunicable diseases (NCDs) [Internet]. WHO. 2015 [cited 2016 Mar 17]. Available from: http://www.who.int/features/2015/ncd-india/en/

39. Athanasakis E, Karavasiliadou S, Styliadis I. The factors contributing to the risk of sudden infant death syndrome. Hippokratia. 2011;15(2):127-31.

40. World Bank. Mortality rate, under-5 (per 1,000) [Internet]. 2015 [cited 2016 Apr 7]. Available from: http://data.worldbank.org/indicator/SH.DYN.MORT

41. Kerry Cullinan. South Africa far from targets to reduce maternal, infant mortality [Internet]. Health-e. 2013 [cited 2016 Feb 10]. Available from: http://www. health-e.org.za/2013/10/29/south-africa-far-targets-reduce-maternal-infantmortality/

42. South African Department of Health. Millennium Development Goals, Goal 4: Reduce child mortality [Internet]. 2010. Available from: http://www.statssa.gov. za/MDG/2010_MDG_GOAL_4_REDUCE_CHILD_MORTALITY.pdf

43. South African Summit on the Prevention and Control of NCD's. South African declaration on the prevention and control of non-communicable diseases [Internet]. 2011. Available from: http://www.health.uct.ac.za/usr/health/ research/groupings/cdia/downloads/SA_NCD_Declaration.pdf

44. Mangiaracina G, Palumbo L. [Smoking while driving and its consequences on road safety]. Ann Ig Med Prev E Comunità. 2007;19(3):253-67.

45. WHOFCTC. The economic and health benefits of tobacco consumption [Internet]. 2015. Available from: http://apps.who.int/iris/bitstream/10665/179423/1/WHO_ NMH_PND_15.6_eng.pdf?ua=1

46. WHO Tobacco Free Initiative.Tobacco and poverty, a vicious circle [Internet] 2004. Available from: http://www.who.int/tobacco/communications/events/ wntd/2004/en/wntd2004_brochure_en.pdf

47. BRICS. Chapter 1: Economic and Social Indicators Comparison of BRICS Countries. BRICS joint statistical publication. [Internet]. 2012. Available from: http://mospi.nic.in/mospi_new/upload/bricks_2012_24aug12/htm/CHAPTER1.pdf

48. The tobacco atlas. Tobacco and poverty [Internet].The Tobacco Atlas. 2015 [cited 2015 Dec 23]. Available from: http://www.tobaccoatlas.org/topic/tobaccopoverty/

49. Ministry of health and Family Welfare Government of India. Economic Burden of Tobacco Related Diseases in India. Executive Summary. 2014.

50. Preeti S, Raut D K. Prevalence and Pattern of Tobacco Consumption in India. Int Res J Social Sci. 2012;1(4):36-43.
51. Groenewald $\mathrm{P}$, Vos $T$, Norman $R$, Laubscher $R$, van Walbeek $C$, Saloojee $Y$, et al. Estimating the burden of disease attributable to smoking in South Africa in 2000. South Afr Med J Suid-AfrTydskrVirGeneeskd. 2007;97(8 Pt 2):674-81.

52. van Walbeek C. The economics of tobacco control in South Africa. 2005; Available from: http://tobaccoecon.org/wp-content/uploads/2014/09/vanwalbeekcp-the-economics-of-tobacco-control-in-south-africa1.pdf

53. WHO, World Economic Forum. Reducing the Economic Impact of NonCommunicable Diseases in Low- and Middle-Income Countries [Internet]. 2011. Available from: http://www.who.int/nmh/publications/best_buys_summary.pdf

54. van Walbeek C. Measuring changes in the illicit cigarette market using government revenue data: the example of South Africa. Tob Control. 2014;23(e1):e69-74

55. Saloojee Y, Dagli E. Tobacco industry tactics for resisting public policy on health. Available from: http://www.who.int/bulletin/archives/78\%287\%29902.pdf

56. Baleta A. Tough anti-tobacco legislation moves forward in South Africa. The Lancet. 1998;352(9140):1609.

57. White A. The Great South African Smokeout. 2001 [cited 2016 Feb 8];Vol. 22. Available from: http://www.multinationalmonitor.org/mm2001/01jan-feb/corp8. html

58. WHO MPOWER. MPOWER: Six policies to reverse the tobacco epidemic [Internet]. 2008. Available from: http://www.who.int/tobacco/mpower/mpower_ report six policies_2008.pdf

59. World Bank Small Grant Programme. Monitoring \& Evaluation [Internet]. 2007. Available from: http://siteresources.worldbank.org/INTBELARUS/Resources/ M\&E.pdf

60. WHO FCTC. Monitoring is a critical tobacco control activity [Internet]. 2008. Available from: http://www.who.int/tobacco/mpower/publications/en_tfi_ mpower_brochure_m.pdf

61. Durkin S, Brennan E, Wakefield M. Mass media campaigns to promote smoking cessation among adults: an integrative review. Tob Control. 2012;21(2):127-38.

62. WHO. Leading cause of death, illness and impoverishment [Internet].WHO. 2015 [cited 2016 Feb 11]. Available from: http://www.who.int/mediacentre/ factsheets/fs339/en/

63. WHO. Prevention is better than cure, say Romanian doctors. Bull World Health Organ. 2011;89(4):248-9. 